\title{
PENGARUH VARIASI JARAK ELEKTRODA DAN WAKTU TERHADAP PH DAN TDS LIMBAH CAIR BATIK MENGGUNAKAN METODE ELEKTROKOAGULASI
}

\author{
Yoza Fendriani*, Nurhidayah, Linda Handayani, Rustan, Samsidar, Mardian Peslinof \\ Prodi Fisika, Fakultas Sains dan Teknologi, Universitas Jambi, Mendalo Indah, Jambi, 36361, Indonesia \\ *email:yozafendriani@unja.ac.id
}

\begin{abstract}
ABSTRAK
Peningkatan produksi suatu industri selalu diikuti oleh peningkatan produksi limbah yang dihasilkan. Industri batik skala rumah tangga umumnya juga belum memiliki instalasi pengolahan limbah cair sehingga limbah langsung dibuang ke lingkungan atau badan air. Hal ini memberikan dampak yang buruk terhadap lingkungan. Penelitian ini bertujuan membuat suatu teknologi pengolahan limbah cair menggunakan metode elektrokoagulasi yang diintegrasikan dengan sistem filter dan menguji efisiensinya terhadap kenaikan kadar keasaman limbah dan penurunan jumlah padatan terlarut (TDS) dari limbah tersebut. Sampel yang digunakan merupakan limbah batik dari salah satu industri batik di kota Jambi sejumlah 20 liter. Elektroda yang digunakan terbuat dari aluminium sebagai anoda dan besi sebagai katoda. Jumlah katoda dan anoda masing-masingnya adalah 4 buah dengan ukuran $60 \mathrm{~cm} \times 30 \mathrm{~cm} \times 3 \mathrm{~cm}$. Tegangan yang digunakan adalah $40 \mathrm{Volt}$ dengan memvariasikan jarak antar elektroda dan waktu pengolahan limbah. Sebelum limbah diolah menggunakan reaktor dilakukan penyaringan dan analisis karakter awal terlebih dahulu. Hasil penelitian menunjukkan efisiensi reaktor elektrokoagulasi dalam menaikkan $\mathrm{pH}$ mencapai 60\% hingga 123\% dengan rata-rata kenaikan pH 80,83\%. Pada perlakuan yang sama, metode elektrokoagulasi memiliki efisiensi dalam menurunkan konsentrasi TDS hingga 50,56\%. Hal ini menunjukkan bahwa metode ini cukup efektif dalam proses pengolahan limbah cair hingga sesuai baku mutu limbah cair.
\end{abstract}

Kata Kunci: Elektrokoagulasi; pH; TDS; Limbah Cair

\section{ABSTRACT}

[Title: The Effect of Electrode Distance and Time Variations on pH and TDS of Batik Wastewater Using Electrocoagulation Method] Increased production of an industry is always followed by waste produced. The household-scale batik industry generally also does not yet have a liquid waste treatment plant, so liquid waste is directly discharged into the environment. This has an adverse impact on the environment. This study aims to create a wastewater treatment technology using electrocoagulation method that is integrated with a filter system and to test its efficiency for increasing acidity levels of waste and decreasing the amount of total dissolved solids (TDS) from the waste. The sample used is batik wastewater from one of the batik industries in Jambi with amount 20 liters. The electrodes use are made of aluminium as the anode and iron as the cathode. The number of of cathodes and anodes is 4 each with dimensions of $60 \mathrm{~cm} \times 30 \mathrm{~cm} \times 3 \mathrm{~cm}$. The voltage used is 40 Volt by varying the distance between electrodes and time of treatment. Before the wastewater was treated using the reactor, the liquid waste was filtered and analyzed the initial character. The results showed that the efficiency of electrocoagulation reactor in increased the $\mathrm{pH}$ reached $60 \%$ to $123 \%$ with average $80,83 \%$. In the same treatment, the electrocoagulation method has efficiency in reducing TDS concentrations up to $50.56 \%$. The result shows that this method is quite effective in the processing of liquid waste until it meets the wastewater quality standard.

Keywords: Electrocoagulation; pH; TDS; Liquid Waste

\section{PENDAHULUAN}

Batik merupakan karya seni warisan leluhur Indonesia dan merupakan salah satu komiditi unggulan Provinsi Jambi. Dalam proses produksinya, batik banyak menggunakan zat pewarna dan menghasilkan limbah cair yang terdiri dari logam berat, minyak, dan juga padatan tersuspensi. Limbah yang dihasilkan dari sisa pewarnaan batik biasanya langsung dibuang ke lingkungan. Khususnya di wilayah Jambi, rumahrumah pengrajin batik kebanyakan masih merupakan rumah panggung yang merupan rumah khas Provinsi Jambi sehingga limbah cair yang dihasilkan langsung dibuang ke bawah rumah panggung. Hal ini sangat merugikan lingkungan serta menimbulkan bau. Semakin meningkatnya produksi batik maka limbah cair yang dihasilkan juga akan mengalami peningkatan. Jika volume 
limbah sudah banyak, biasanya limbah cair disedot menggunakan mobil tangki kemudian limbah dibuang ke sungai. Hal ini justru menimbulkan dampak lingkungan yang lebih luas terutama pada organisme perairan. Oleh karena itu, perkembangan industri batik harus diikuti dengan proses pengolahan limbah yang baik sebelum dibuang ke lingkungan.

Teknologi pengolahan limbah cair batik umumnya dapat dilakukan menggunakan pengolahan secara kimia dan biologi. Namun setiap proses memiliki kelebihan dan kekurangan masing-masing. Pengolahan limbah dengan proses kimia dianggap efektif dalam mengolah limbah secara besar namun juga menimbulkan efek samping pada kesehatan dan pencemaran air karena bahan kimia yang sulit terurai (Vasundevan, 2013). Proses biologi lebih aman karena tanpa menggunakan bahan kimia, namun proses biologi tidak dapat digunakan untuk limbah beracun karena akan membunuh mikroba pengurai (Hao et al, 2000). Pengolahan limbah dengan proses biologi membuat kita harus menjaga kualitas mikroba agar tetap hidup dan aktif dengan cara mengatur $\mathrm{pH}$ dan suhu air limbah. Keterbatasan ini membuat adanya alasan untuk mengembangkan alternatif lain dalam pengolahan limbah cair. Sejauh ini belum ada teknologi pengolahan limbah cair yang cepat, efisien, atau bahkan portable seperti metode elektrokoagulasi. Oleh sebab itu, dengan hadirnya penelitian ini sangat memberi manfaat untuk mengatasi permasalahan lingkungan ini.

Proses elektrokoagulasi merupakan gabungan dari proses elektrokimia dan proses flokulasi-koagulasi (Djajadiningrat, 2004). Elektrokoagulasi merupakan suatu proses koagulasi kontinu menggunakan arus listrik searah melalui proses elektrokimia. Pada anoda dalam metode elektrokoagulasi terjadi pelepasan koagulan aktif berupa ion logam ke dalam larutan. Sedangkan pada katoda terjadi reaksi elektrolisis berupa pelepasan gas hidrogen (Holt dkk, 2002). Elektrokoagulasi mampu menyisihkan berbagai polutan dalam air, yaitu partikel tersuspensi, logam-logam berat, zat pewarna, dan lain-lain (Wahyulis dkk, 2014). Metode ini memiliki kelebihan tanpa menggunakan zat kimia namun efisiensinya cukup tinggi serta dari segi biaya juga cukup ekonomis karena bahan-bahan yang digunakan sederhana dan mudah didapat.

Penelitian ini bertujuan mengolah limbah cair menggunakan metode elektrokoagulasi yang diintegrasikan dengan sistem filter. Untuk tahap pertama ini kami melakukan uji coba teknologi skala laboratorium dengan memvariasikan jarak antar elektroda dan waktu pengolahan yaitu 15 menit dan 45 menit. Parameter yang diuji adalah kadar keasaman $(\mathrm{pH})$ dan TDS (Total Disolved Solid).

\section{METODE}

Limbah cair yang digunakan sebagai sampel penelitian merupakan hasil akhir dari proses pembatikan pada salah satu industri batik di kota Jambi. Volume sampel limbah cair batik yang dianalisis sejumlah 20 liter. Sebelum dilakukan treatment menggunakan reaktor, limbah yang diambil dari lokasi produksi disaring agar tidak ada sampah yang turut masuk serta dianalisis terlebih dahulu karakter awalnya. Karakterisasi awal meliputi $\mathrm{pH}$ dan TDS menggunakan alat ukur $\mathrm{pH}$ meter dan TDS meter dan dilakukan berulang hingga tiga kali pada sampel yang sama.

Total Disolved Solid (TDS) atau padatan terlarut total adalah bahan-bahan terlarut dan koloid yang tidak tersaring pada kertas saring berdiameter $0,45 \mu \mathrm{m}$. Pengukuran TDS menggunakan alat TDS meter menampilkan satuan part per million (ppm) atau sama dengan miligram per liter $(\mathrm{mg} / \mathrm{l})$. Sampel yang akan diukur kadar TDS nya harus diaduk dulu agar zat-zat yang terkandung di dalamnya tersebar merata dan homogen.

Dalam proses elektrokoagulasi, elektroda berfungsi sebagai penghantar arus listrik ke sistem agar terjadi reaksi dan mengakibatkan terjadi perubahan kimia (Masthura dan Jumiati, E, 2017). Elektroda yang digunakan pada penelitian ini adalah elektroda dari bahan aluminium yang berfungsi sebagai anoda dan elektroda dari bahan besi sebagai katoda. Jumlah elektroda yang digunakan adalah 4 elektroda besi dan 4 elektroda alumunium dengan ukuran yang sama masingmasingnya; panjang $60 \mathrm{~cm}$, lebar $30 \mathrm{~cm}$, dan tebal $3 \mathrm{~cm}$. Elektroda dialiri arus searah sehingga kation bergerak ke katoda dan anion bergerak ke anoda yang mengakibatkan terbentuknya flokulan yang berfungsi mengikat kontaminan limbah (Gunawan, 2016).

Reaktor limbah yang digunakan dirancang terintegrasi dengan filter serta menggunakan peralatan yang mudah didapatkan di pasaran. Reaktor sederhana bisa menggunakan jerigen yang diletakkan di atas rak yang kokoh. Filter terbuat dari bak yang diisi dengan pasir dan kerikil. Hal ini bertujuan ketika sistem ini dimanfaatkan oleh industri untuk mengolah limbah, maka dapat dibuat dan diadaptasi dengan mudah. Setelah alat 
dan bahan diinstalasi, sampel limbah dimasukkan dalam reaktor, kemudian elektroda dalam reaktor dihubungkan dengan power supply. Kutub positif dihubungkan ke elektroda besi dan kutub negatif dihubungkan dengan elektroda aluminium. Hal yang penting diingat adalah untuk memastikan tegangan yang dihasilkan power supply adalah tegangan DC. Jika tegangan yang digunakan adalah tegangan AC maka akan sangat berbahaya. Alatalat yang digunakan pada penelitian ini dapat dilihat pada Gambar 1 berikut:

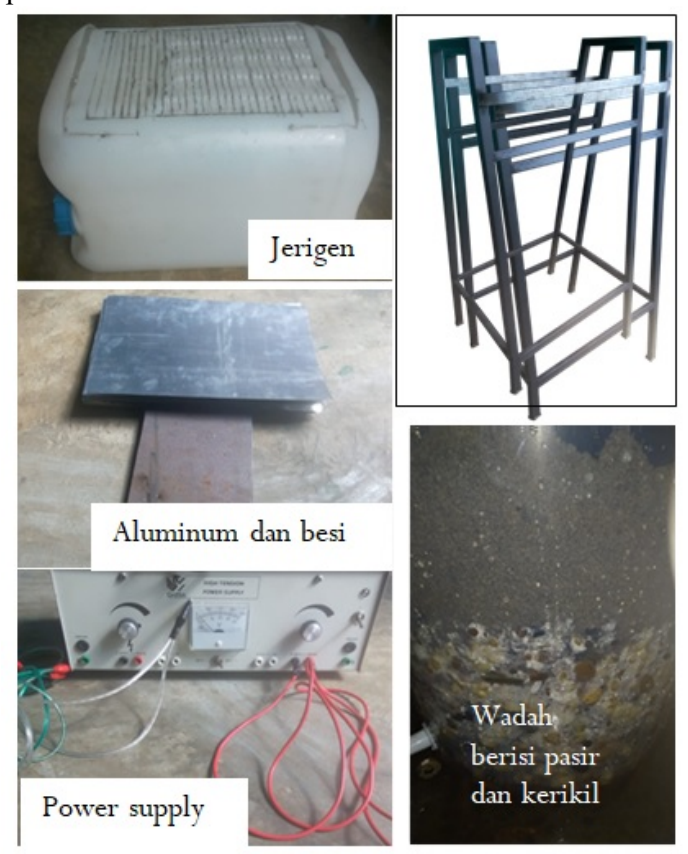

Gambar 1. Alat dan bahan yang digunakan

Adapun detail rangkaian alat yang digunakan dapat dilihat pada Gambar 2.

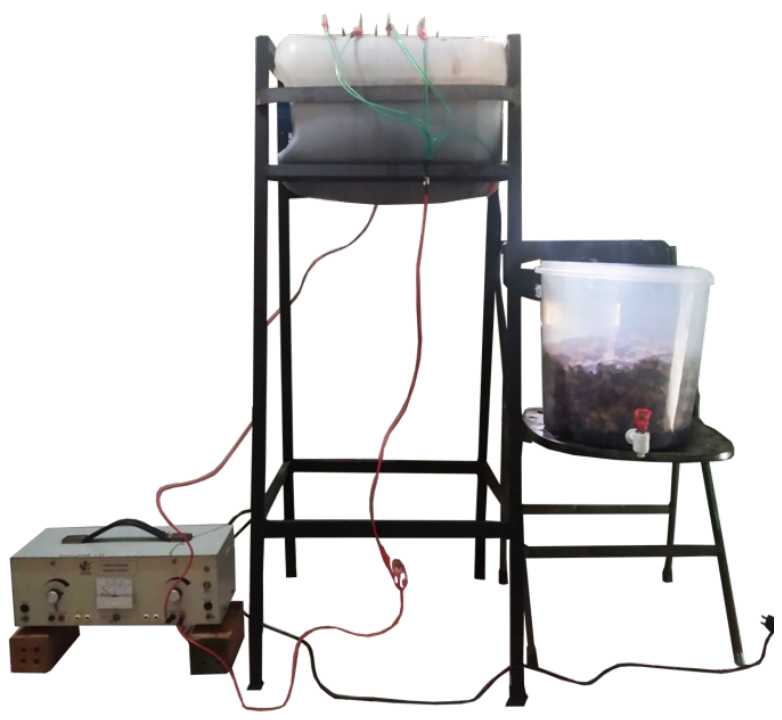

Gambar 2. Rangkaian reaktor limbah terintegrasi sistem filter
Pelaksanaan penelitian ini bertujuan untuk mengetahui efisiensi sistem reaktor dalam mengolah limbah sehingga memenuhi standar baku mutu limbah cair yaitu pada parameter kadar keasaman $(\mathrm{pH})$ dan Total Disolve Solid (TDS). Tegangan yang digunakan adalah 40 volt dengan variasi jarak elektroda yang digunakan adalah $3 \mathrm{~cm}$ dan $5 \mathrm{~cm}$. Sedangkan variasi waktu proses elektrokoagulasi yang digunakan adalah 15 menit dan 45 menit.

\section{HASIL DAN PEMBAHASAN}

\section{Karakterisasi Awal Limbah}

Karakterisasi awal limbah dilakukan untuk mengetahui kondisi awal sampel limbah batik dan mengetahui seberapa parah kondisi limbah tersebut. Parameter yang diidentifikasi adalah kadar keasaman (pH) dan nilai TDS awal limbah. Adapun nilai $\mathrm{pH}$ awal limbah yaitu 3 dan nilai TDS nya adalah $1.777 \mathrm{mg} / \mathrm{L}$.

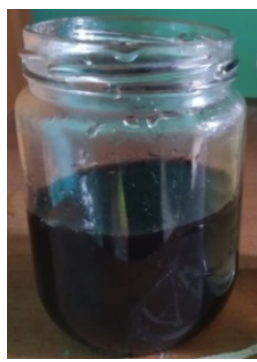

Gambar 3. Limbah cair batik

Berdasarkan pada standar baku mutu limbah yang sesuai dengan Keputusan Menteri Negara Lingkungan Hidup Nomor: Kep51/MENLH/10/1995, nilai baku mutu pH air yang aman dibuang ke lingkungan berada pada rentang 6,0 - 9,0 maka dapat dikatakan nilai $\mathrm{pH}$ sampel ini jauh dari standar. Oleh karena itu sangat berbahaya jika limbah langsung dibuang ke lingkungan. Selanjutnya, merujuk pada dari Peraturan Pemerintah No 82 Tahun 2001 tanggal 14 Desember 2001 Tentang Pengolahan Kualitas air dan Pengendalian Pencemaran Air yang hanya memperbolehkan kandungan TDS sebesar $1000 \mathrm{mg} / \mathrm{L}$ di dalam air limbah sungai sehingga nilai TDS $1.777 \mathrm{mg} / \mathrm{l}$ termasuk dalam kategori air yang buruk. Oleh sebab itu, karakterisasi awal limbah ini menjadi suatu tanda bahwa limbah batik ini harus dikelola terlebih dahulu sebelum dibuang ke lingkungan.

\section{Karakterisasi Hasil Pengolahan Limbah}

Limbah cair batik yang telah diolah menggunakan reaktor elektrokoagulasi dan sistem filter kemudian diukur kembali kadar keasaman dan TDS nya. Adapun hasil karakterisasi ditambpilkan pada gambar 4 berikut: 


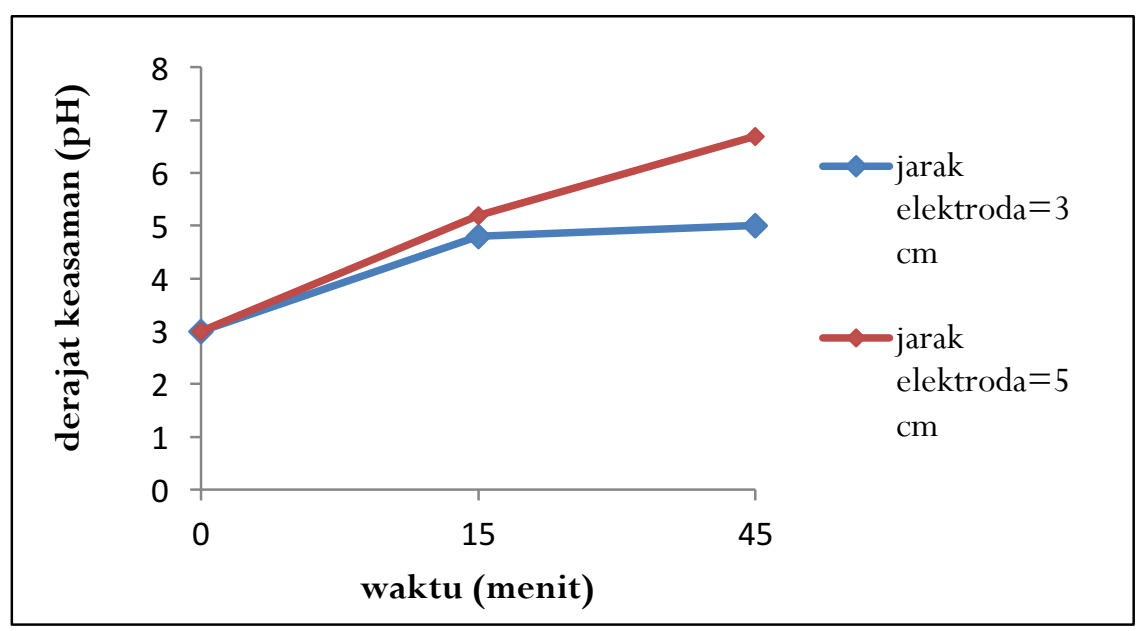

Gambar 4. Grafik perubahan pH limbah terhadap waktu

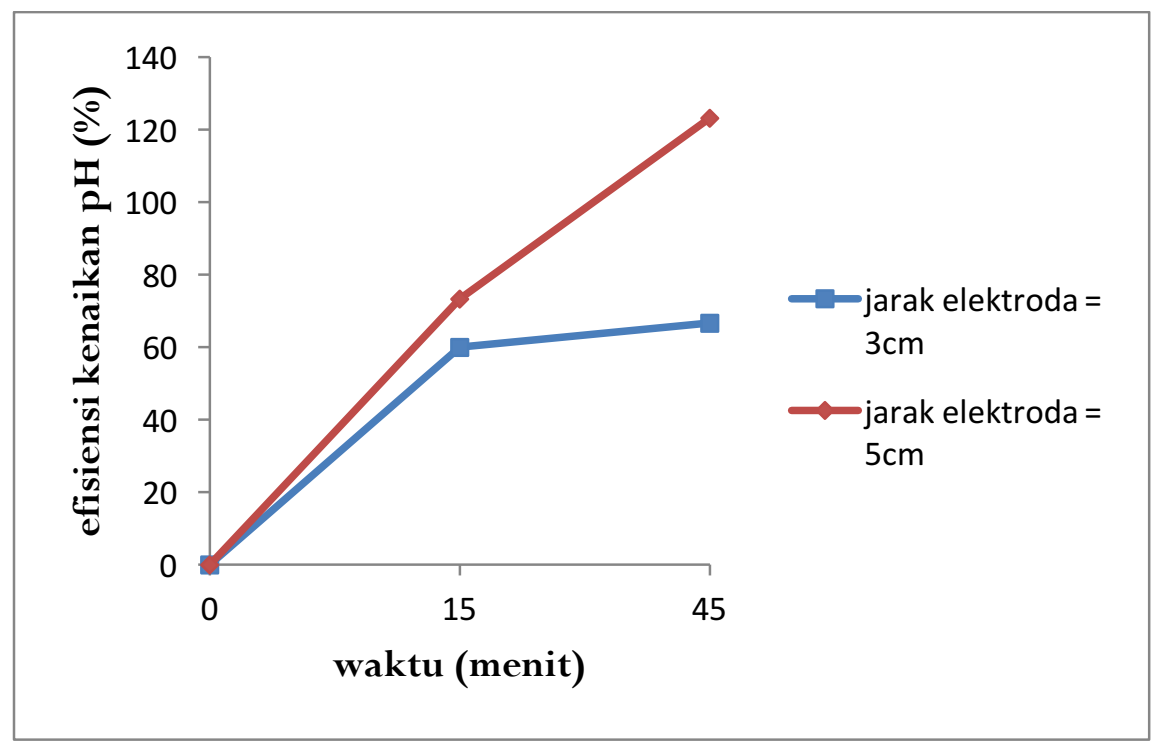

Gambar 5. Grafik efisiensi kenaikan pH limbah

Nilai pH meningkat setelah dilakukan proses elektrokoagulasi . Berdasarkan grafik pada Gambar 4, dapat diketahui bahwa proses elektrokoagulasi dengan variasi jarak elektroda dan waktu kontak yang memenuhi standar baku mutu nilai $\mathrm{pH}>6$ yaitu pada waktu 45 menit dan jarak antar elektroda $5 \mathrm{~cm}$ dengan nilai $\mathrm{pH}$ yang diperoleh yaitu 6,7. Kenaikan $\mathrm{pH}$ terjadi pada setiap perlakuan sejalan dengan bertambahnya lama waktu perlakuan dan jarak antar elektroda. Peningkatan $\mathrm{pH}$ mengakibatkan penurunan kadar polutan pada limbah. Menurut penelitian Niam et al (2007), peningkatan nilai pH disebabkan karena pada proses elektrokoagulasi terjadi akumulasi peningkatan ion hidroksida $\left(\mathrm{OH}^{-}\right)$. Banyaknya jumlah ion hidroksida menyebabkan energi yang dibutuhkan pembentukan gas hidrogen atau oksigen semakin rendah sehingga akan dihasilkan gelembung gas yang banyak. Jumlah gelembung udara yang meningkat juga meningkatkan kinerja flotasi (Yolanda, 2015).
Nilai pH larutan mempengaruhi efisiensi dan efektifitas elektrokoagulasi secara keseluruhan. Efisiensi kenaikan $\mathrm{pH}$ yang terjadi pada jarak elektroda $3 \mathrm{~cm}$ dengan waktu kontak 15 menit dan 45 menit masingmasingnya adalah 60\% dan 66,67\%. Sedangkan untuk jarak elektroda $5 \mathrm{~cm}$ dengan waktu kontak 15 menit didapatkan efisiensi kenaikan pH sebesar 73,33\%. Untuk jarak elektroda $5 \mathrm{~cm}$ dengan waktu proses elektrokoagulasi selama 45 menit didapatkan efisiensi kenaikan pH sebesar 123,33\%, nilai efisiensi yang besar ini menyatakan bahwa proses elektrokoagulasi sangat efisien untuk menaikkan kadar keasaman limbah cair dengan rata-rata efisiensi kenaikan $\mathrm{pH}$ adalah 80,83\%. Nilai efisiensi ini cukup besar sehingga dapat dikatakan bahwa proses elektrokoagulasi efektif dalam meaikkan kadar $\mathrm{pH}$ limbah. 


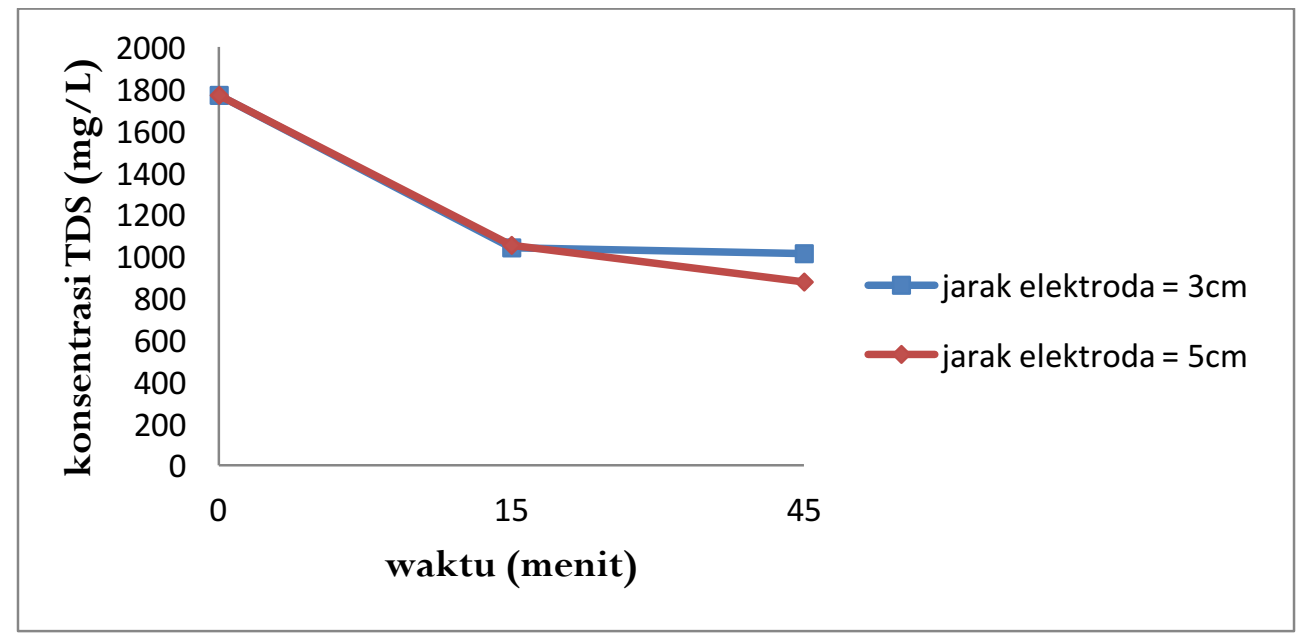

Gambar 6. Grafik perubahan konsentrasi TDS limbah terhadap waktu

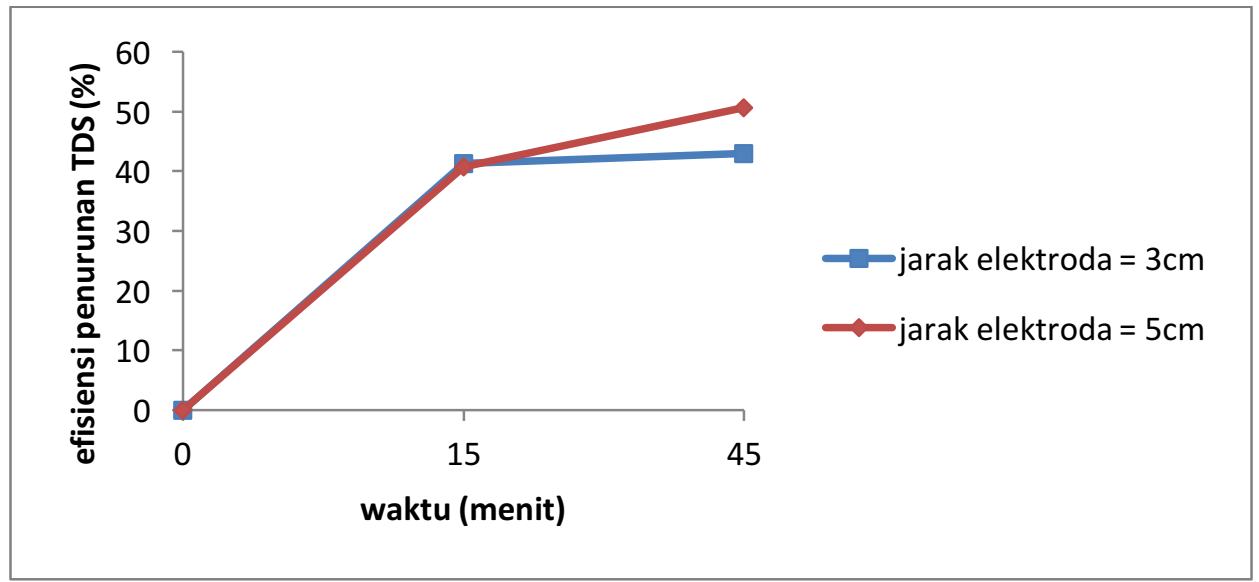

Gambar 7. Grafik efisiensi penurunan konsentrasi TDS limbah

TDS (Total Disolve Solid) merupakan ukuran zat terlarut baik itu zat organik maupun anorganik yang terdapat dalam larutan. Berdasarkan Gambar 6, dapat dilihat bahwa nilai TDS sebelum dan setelah dilakukan treatment mengalami penurunan dan rata-rata mendekati nilai standar baku mutu. Pada waktu proses elektrokoagulasi selama 15 menit, nilai TDS yang dihasilkan dengan jarak elektroda $3 \mathrm{~cm}$ maupun $5 \mathrm{~cm}$ tidak terlalu jauh berbeda. Pada jarak elektroda $3 \mathrm{~cm}$ dihasilkan TDS sebesar $1.040 \mathrm{mg} / \mathrm{l}$ sedangkan pada jarak elektroda $5 \mathrm{~cm}$ didapatkan TDS sebesar $1.050 \mathrm{mg} / \mathrm{l}$. Kedua nilai ini hampir mendekati nilai standar baku mutu sebesar $1.000 \mathrm{mg} / \mathrm{l}$. Pada waktu proses elektrokoagulasi selama 45 menit, nilai TDS pada jarak elektroda didapatkan sebesar $1.010 \mathrm{mg} / \mathrm{l}$. Dan nilai TDS terbaik yang memenuhi standar baku mutu terjadi pada waktu 45 menit dengan jarak elektroda $5 \mathrm{~cm}$ yaitu sebesar 875 $\mathrm{mg} / \mathrm{l}$.

Menurut WHO, selama air dalam kategori tawar maka kandungan mineral dalam air tidak akan berpengaruh terhadap kesehatan. Namun, kadar padatan yang tinggi juga bisa merupakan indikator bahwa ada kontaminan berbahaya, seperti zat sulfat dan bromida arsenik yang ada di dalam air tersebut. Perubahan dalam konsentrasi TDS dapat berbahaya karena akan menyebabkan perubahan salinitas, perubahan komposisi ion-ion, dan toksisitas masing-masing ion. Perubahan salinitas ini bisa menganggu keseimbangan biota air, biodiversitas, serta menyebabkan toksisitas yang tinggi pada tahapan hidup suatu organisme (Weber-Scannel and Duffy, 2007).

Berdasarkan Gambar 7, dapat terlihat efisiensi yang terjadi pada jarak elektroda $3 \mathrm{~cm}$ dengan waktu proses elektrokoagulasi 15 menit didapatkan sebesar 41,24\%. Sedangkan untuk efisiensi pada waktu 45 menit denganjarak antar elektroda yang sama yaitu sebesar 42,94\%. Pada jarak elektroda $5 \mathrm{~cm}$ dan waktu proses elektrokoagulasi selama 15 menit menunjukkan tingkat efisiensi 40,68 \%. Kemudian efisiensi terbesar terjadi pada jarak elektroda $5 \mathrm{~cm}$ menggunakan waktu proses elektrokoagulasi selama 45 menit yaitu sebesar 50,56\%. Nilai ini menyatakan bahwa proses elektrokoagulasi cukup baik dalam menurunkan konsentrasi TDS dalam air limbah sehingga teknologi ini dapat dikembangkan lebih lanjut dengan mencari kondisi optimal masingmasing parameternya. 


\section{KESIMPULAN DAN SARAN}

\section{Kesimpulan}

1. Metode elektrokoagulasi memiliki rata-rata efisiensi sebesar 80,83\% dalam menaikkkan $\mathrm{pH}$ limbah cair batik dengan range 60\% hingga 123\%. Nilai efisiensi kenaikan $\mathrm{pH} 60 \%$ didapat pada jarak elektroda $3 \mathrm{~cm}$ dan waktu 15 menit sedangkat efisiensi mencapai $123,33 \%$ pada jarak elektroda 5 cm dan waktu 45 menit.

2. Pada perlakuan yang sama, metode elektrokoagulasi memiliki efisiensi dalam menurunkan konsentrasi TDS 40\% hingga 50,56\%. Efisiensi penurunan TDS $40 \%$ diperoleh pada jarak antar elektroda $3 \mathrm{~cm}$ dan waktu proses 15 menit dan efisiensi 50,56\% pada jarak antar elektroda $5 \mathrm{~cm}$ dan waktu proses 45 menit.

3. Pada volume limbah sebanyak 20 liter dan perlakuan menggunakan tegangan 40 volt, metoda elektrokuagulasi dengan jarak elektroda $5 \mathrm{~cm}$ dan waktu 45 menit sudah memenuhi standar baku mutu limbah yang dapat dibuang ke lingkungan.

Saran

Metode ini dapat diadopsi oleh masyarakat untuk mengolah limbah cair batik ataupun limbah cair industri lainnya sebelum dibuang ke lingkungan. Jika metode ini diadopsi, disarankan penggunaan pompa untuk melakukan perpindahan air limbah ke reaktor.

\section{UCAPAN TERIMAKASIH}

Terimakasih kepada Universitas Jambi yang memberikan dukungan dana sehingga penelitian ini dapat dilaksanakan dengan baik.

\section{DAFTAR PUSTAKA}

Djajadiningrat, Asiz H. 2004. Pengolahan Limbah Cair Tanpa Bahan Kimia. ITB : Bandung

Gunawan, D.A. 2016. Elektrokoagulasi Menggunakan Aluminium sebagai pre-treatment pada Mikrofiltrasi Air Permukaan yang Mengandung NOM. Teknik Kimia, Institut Teknologi Bandung.

Hao, O.J., Kim, H., Chiang, P.C., 2000. Decolorization of wastewater. Crit. Rev.
Environ.Sci. Technol. 30 (4), 449e505

Holt, P. K., Barton, G. W., Wark, M., and Mitchell, C. A. 2002. A Quantitative Comparison Between Chemical Dosing and Electrocoagulation. Colloids and Surfaces A: Physicochem. Eng.

Keputusan Menteri Negara Lingkungan Hidup Nomor : Kep-51/Menlh/10/1995 Tentang Baku Mutu Limbah Cair Bagi Kegiatan Industri

Masthura dan Jumiati, E. 2017. Peningkatan Kualitas Air Menggunakan Metode Elektrokoagulasi dan Filter Karbon. Jurnal Ilmu Fisika dan Teknologi, Vol. 1, No. 2, 2017, 1-6.

Ni'am, M.F., Othman F., Sohaili J. Dan Fauzia Z. 2007. Removal of COD and Turbididty to Improve Wastewater Quality using Electrocoagulation Technique. The Malaysian Journal of Analytical Science, 11(1):198-205

Vasudevan, S., Lakshmi, J., Sozhan, G., 2013. Electrochemically assisted coagulation for the removal of boron from water using zinc anode. Desalination 310, 122e129

Wahyulis N.C, Ulfin I, Harmami. 2014. Optimasi Tegangan pada Proses Elektrokoagulasi Penurunan Kadar Kromium dari Filtrat Hasil Hidrolisis Limbah Padat Penyamakan Kulit. Jurnal Sains dan Seni Pomits. Volume 3 (No 2) 2337-3520. Fakutlas MIPA. Institut Teknologi Sepuluh November (ITS). Surabaya

Weber-Scannell, P.K., L.K. Duffy. 2007. Effect of Total Dissolved Solids on Aquatic Organisms: A Review of Literature and Rrecommendation for Salmonid Species. American Journal of Environmental Sciences. 3(1). 1-6.

Yolanda, Gita Melisa. 2015. Pengolahan Limbah Cair Laboratorium dengan Proses Elektrokoagulasi. Skripsi. Institut Pertanian Bogor 